\title{
Dysprosody after severe closed head injury: an acoustic analysis
}

\author{
C Samuel, A Louis-Dreyfus, J Couillet, B Roubeau, S Bakchine, B Bussel, P Azouvi
}

\begin{abstract}
Objectives-Neurological speech disorders (dysarthria and dysprosody) are known to be frequent sequelae after severe closed head injury. These disorders may dramatically alter communicative intent and accentuate social isolation. The aim was to provide an instrumental evaluation for prosodic production in a group of patients with severe closed head injury and to determine the correlations between prosodic production and neurobehavioural status.

Methods-Fifteen patients, at the subacute stage after severe closed head injury, were studied and compared with 11 controls, matched for age, sex, and duration of education. Each subject was required to read aloud a French sentence 'Je m'en vais samedi matin" (I am leaving saturday morning) under six different prosodic intonations (neutral, affirmation, interrogation, happiness, sadness, anger). The recorded sentences were analysed using a sound signal analysis software (Signalyse) allowing the measurement of signal intensity and fundamental frequency. Statistical analyses were carried out using repeated measures analysis of variance (ANOVA).
\end{abstract}

Service de

Rééducation

Neurologique, Hôpital

Raymond Poincaré

(AP-HP), Université

Paris V, Garches,

France

C Samuel

A Louis-Dreyfus

J Couillet B Bussel

P Azouvi

Service d'ORL, Hôpital Tenon, Paris, France

B Roubeau

Fédération de

Neurologie, Hôpital de la Salpétrière, Paris,

France

S Bakchine

Correspondence to: Dr Christiane Samuel, Department of Neurological Rehabilitation, Raymond Poincaré Hospital, 92380 Garches, France.

Received 6 May 1997 and in revised form 9 September 1997

Accepted 17 September 1997

Results-Patients with closed head injury were significantly less able than controls to modulate speech output (pitch and intensity) according to prosodic context. This deficit was particularly pronounced for the intonation feature of anger, question, and statement. No consistent correlations could be found between prosodic production and cognitive or behavioural data.

Conclusions-Acoustic analysis of pitch and intensity may show impairments of prosodic production after severe closed head injury, which may be useful in rehabilitation planning. This impairment does not seem to reflect the eventual cognitive and behavioural deficits of the patients, but rather a specific disorder of modulation of speech output.

(F Neurol Neurosurg Psychiatry 1998;64:482-485)

Keywords: dysprosody; head injury; acoustic analysis

The aim of the present study was to provide an instrumental evaluation of prosodic production in survivors of severe closed head injury. Neurological speech disorders (dysarthria and dysprosody) have often been reported after severe closed head injury. ${ }^{1-6}$ They may interfere with a patient's ability to communicate even if cognitive and language levels have recovered. ${ }^{5}$ Dysprosody is a failure to process suprasegmental linguistic and emotional features of language. It may dramatically alter communicative intent and accentuate social isolation. ${ }^{7-9}$ In a recent study of perceptual speech characteristics exhibited by patients with closed head injury, Theodoros et $a l^{4}$ found that prosodic disturbance was one of the most prominent dysfunctions of the speech production process. These authors stressed that perceptual findings need to be verified by objective instrumental assessment of each of the motor subsystems of the speech production mechanism. Such analysis could provide an objective assessment of speech disorders, disclose disorders which are difficult to perceive by auditory means, and detail the true nature of the speech disorders after closed head injury. Only recently has instrumental acoustic analysis of speech been developed for clinical practice. ${ }^{10}$ Theodoros et $a l^{4}$ described patients with closed head injury who had what is perceived as reduced variation of pitch and deviations of volume. Consequently, in this study we used an instrumental acoustic analysis to measure the fundamental frequency and the intensity of speech within various intonations in patients with severe closed head injury.

\section{Subjects and methods}

SUBJECTS

The patient group consisted of 15 native French speakers. They all had sustained a severe closed head injury, as defined by an initial score of 8 or less on the Glasgow coma scale (GCS). ${ }^{11}$ This criteria was used as the GCS has been repeatedly recognised as a reliable measure to assess the severity of brain injury. ${ }^{12}$ However, recent studies have suggested that duration of post-traumatic amnesia may be a more useful index. ${ }^{13}$ In this study, all patients had a post-traumatic amnesia of one day or more, and most of them of more than one week, corresponding respectively to a severe and very severe brain injury according to the taxonomy suggested by Jennett and Teasdale. ${ }^{14}$ There were 12 male and three female patients, mean age 29.0 (SD 10.2), range 16-47 years. Their mean duration of education was 11.5 (SD 2.3), range 8-18 years. Mean Initial GCS score was 6.8 (SD 1.32), range $4-8$ and mean coma duration was 20 (SD 10.9), range 1-45 days. They were tested on average 6.1 (SD 4.17), range: $1.5-18$ months postinjury). At the time of inclusion they were all out of posttraumatic amnesia, as defined by a score $\geqslant 75$ on the Galveston orientation and amnesia test 
(mean score: 87.5 (SD 7.9), range $76-100$ ). ${ }^{15}$ Patients were not included in the study if they had any aphasic disorder which could interfere with the task. The presence of aphasia was assessed by means of a standardised French naming test in which patients were asked to name 80 pictures. ${ }^{16}$ The cut off score is $70 / 80$, and all our patients scored 76 or more on this test. Moreover, as depression is known to alter prosodic output, ${ }^{17}{ }^{18}$ patients with a major depressive syndrome according to DSM III-R ${ }^{19}$ criteria were also excluded. Other criteria for exclusion were previous neurological illness, auditory or visual deficits, vocal cord lesions, and drug or alcohol misuse.

Eleven healthy subjects (eight men and three women), matched for age (mean 30.7 (SD 10.3), range 17-48 years), and duration of education (mean 10.9, (SD 2.3), range 9-19 years) were used as controls. Controls and patients did not differ statistically in age or duration of schooling.

\section{PROCEDURES}

Experimental conditions

Each subject was required to read aloud the same sentence devoid of emotional words twice: "Je m'en vais samedi matin" (I am leaving on saturday morning) under six different prosodic intonations. First, they were asked to read this sentence with a neutral voice, then to use two linguistic intonations (affirmative and interrogative) and three emotional tones (happy, sad, and angry). To be sure that subjects understood the task, the main objectives of the study were given to the subjects, and each trial was preceded by a short explanation (for example, to explain what was meant by a happy tone: "Imagine that you have planned a marvellous trip abroad and you are very happy when you tell your best friend that you'll be leaving next saturday morning"). The six different conditions were always given in the same order (neutral, affirmative, interrogative, happy, sad, angry). For each intonation, two speech samples were required and only the best one according to perceptive judgement was kept for further instrumental analysis. Total experiment duration was about 30 minutes.

\section{Instrumental analysis}

All assessments were given under standard conditions, in constant and quiet surroundings. The microphone was located $30 \mathrm{~cm}$ from the subject's mouth. Speech samples were recorded on an audiotape (Sony Walkman Pro) then secondly digitalised through an analog to digital converter (Mac Recorder) and stored in an Apple Macintosh microcomputer. A sound signal analysis software $\left(\right.$ Signalyse $\left.^{20}\right)$ permitted measurement of signal intensity and fundamental frequency (Fo). Mean Fo was then converted in semitones (according to logarithmic transformation) for each intonation. To control for between subject variability, the ability to modulate prosodic output was assessed by calculating the differences between each prosodic intonation and the neutral condition, for both intensity and Fo. This will be referred to as interintonative variation of intensity and
Fo. Moreover, for affirmative and interrogative intonations, the Fo slopes (in semitones $/ \mathrm{ms}$ ) for the last word ("matin") were computed using the following formula: (maximal-minimal Fo)/duration. Raising pitch at the end of a statement indicates a question and decreasing marks an affirmative intonation. ${ }^{9}$

\section{Cognitive and behavioural assessment}

To control for an effect due to attentional or language deficits, patients also underwent a conventional neuropsychological assessment focusing on the following aspects: short term memory with the digit and visuospatial memory span, attention, and speed of processing by the trail making test (TMT) forms A and $\mathrm{B},{ }^{21}$ and verbal fluency by two measures (animals and words beginning with a $\mathrm{P}$ within two minutes each). A global assessment of neurobehavioural status was also performed by means of the neurobehavioural rating scalerevised (NRS). ${ }^{22-23}$ The NRS-revised test comprises 29 items covering a wide range of cognitive and behavioural aspects of the patient with brain injury, scored from a semistructured interview on a four point scale $(1=$ no trouble, $4=$ severe trouble). The NRS was not performed in three cases. To avoid an effect due to mood disorder, patients were assessed on the Montgomery-Asberg depression rating scale (MADRS). ${ }^{24}$ The NRS and the MADRS were both rated by an independent examiner who was not informed of the results of the speech assessment.

\section{Results}

Statistical analyses were carried out using two (group) by five (intonative conditions) repeated measures analyses of variance (ANOVA) for each of the following dependent variables: mean value of Fo (in semitones) and of signal intensity; mean interintonative variation of Fo, and of signal intensity. No significant main effect of group was found either for mean $F_{0}(F(1,24)=0.62, \mathrm{p}=0.4)$ nor for mean signal intensity $(F(1,24)=2.51$, $\mathrm{p}=0.12$ ). However, a significant main effect of group was found for interintonative variation of Fo $(F(1,24)=5.29, \mathrm{p}<0.05)$, with a significant main effect of condition $(F(4,96)=34.3$, $\mathrm{p}<0.0001)$ and a significant group $\times$ condition interaction $(F(4,96)=3.17, \mathrm{p}<0.02)$. Further comparisons were made for each condition by separate one way ANOVAs. No significant group difference was found for sadness $(F(1$, $24)=0.06, p=0.8$ ). For affirmation, interrogation, and happiness, patients tended to have poorer interintonative variations, but this effect did not reach significance $\left(F_{s}(1,24)\right.$ from 3.01 to $3.99, \mathrm{p}$ values from 0.095 to 0.057$)$. A clearly significant group effect was found for anger only $(F(1,24)=7.95, \mathrm{p}<0.01)$. It was due to a lower value in the patient group. The results are displayed on figure 1 .

Similarly, a significant main effect of group was found for interintonative variation of signal intensity $(F(1,24)=6.49, \mathrm{p}<0.02)$, with a significant main effect of condition $(F(4$, $96)=39.59, \mathrm{p}<0.0001)$ and a significant group 


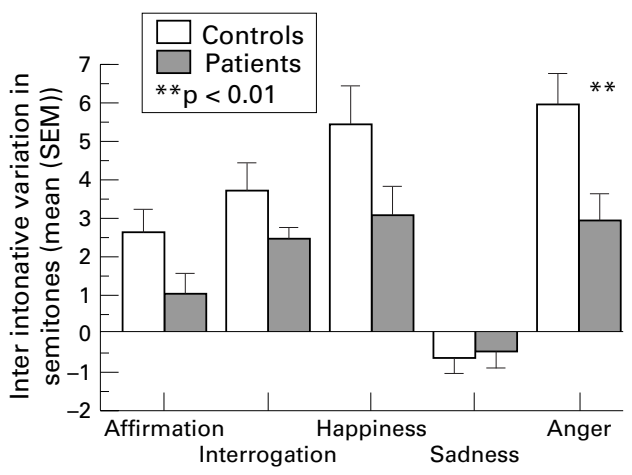

Figure 1 Interintonative variation of Fo. The bars represent the mean (SEM) values (in semitones) of the difference of Fo between each prosodic intonation and the neutral condition.

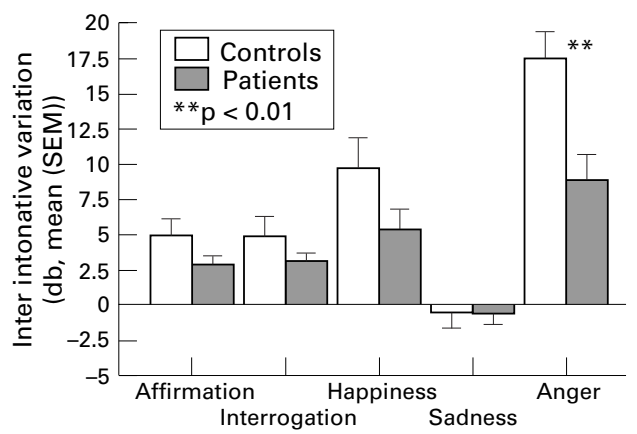

Figure 2 Interintonative variation of signal intensity. The bars represent the mean (SEM) values (in $d B$ ) of the difference of signal intensity between each prosodic intonation and the neutral condition.

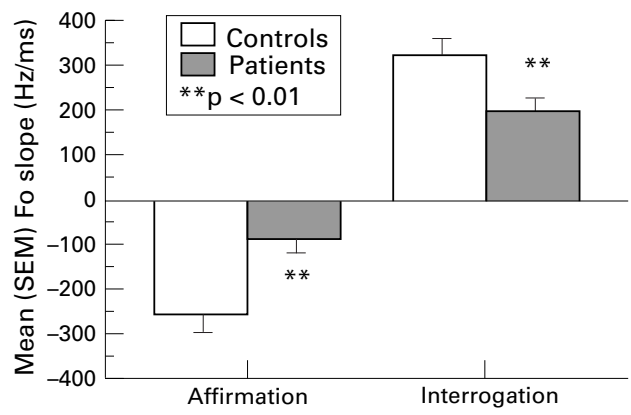

Figure 3 Fo slope (mean (SEM) Hz/ms) for the last word of the sentence under affirmative and interrogative conditions.

$\times$ condition interaction $(F(4,96)=4.47$, $\mathrm{p}<0.01)$. Separate one way ANOVAs showed that only the anger condition had a significant effect of group $(F(1,24)=10.2, \mathrm{p}<0.01)$. For all other conditions, the group effect was nonsignificant $(F s(1,24)$ ranging from 0.006 to 3.01 , $\mathrm{p}$ values $<0.05)$. Figure 2 shows the results.

Mean Fo slopes for affirmative and interrogative intonations were compared in both groups by means of two one way ANOVAs. A significant effect of group was found both for interrogative $(F(1,24)=7.23, \mathrm{p}=0.01)$ and affirmative $(F(1,24)=10.39, \mathrm{p}<0.01)$ slopes. Figure 3 shows that patients had lower slope values, in both conditions.

A correlational analysis was then performed with two objectives: firstly, to search for correlations between prosodic disturbances and severity of injury; secondly, to assess the presence of correlations with other behavioural and cognitive disorders that might potentially interfere with prosodic production. For this purpose, Spearman's rank correlation coefficients have been used. Among the different experimental data, for these analyses we selected only the four measures for which a significant effect of group was found on previous ANOVAs: interintonative variation of Fo and signal intensity for anger, and Fo slopes for affirmative and interrogative intonations. No significant correlation was found with either the GCS score or with coma duration (all $r \mathrm{~s}$ $<0.34$, p values $>0.05$ ), except for a significant correlation between duration of coma and Fo slope for affirmation $(r=0.63, \mathrm{p}=0.02)$. Only few correlations appeared to be significant with neuropsychological assessment. Significant correlations were found between the TMT-B and the Fo slope for interrogation $(r=-0.6$, $\mathrm{p}<0.05$ ), and between the two verbal fluency measures and the inter-intonative variation of signal intensity for anger $(r s=-0.57$ and -0.66 respectively, both $\mathrm{p}$ values $<0.05$ ). The correlations with mood and behavioural assessments were even poorer: no significant correlation was found with the MADRS depression score or with any of the NRS variables (all $r s<0.44, p$ values $>0.05$ ).

\section{Discussion}

The aim of this study was to assess prosodic production after severe closed head injury by means of an instrumental acoustic analysis. Pitch and intensity of the signal were selected because they have been shown to be reliable indexes of prosodic content in both neurological or psychiatric patients. ${ }^{17} 1825$ The main result was that patients with closed head injury were significantly less able than controls to modulate speech output according to prosodic context. This deficit contrasted with the absence of any significant difference between patients and controls for mean values of pitch and intensity of the acoustic signal. Patients, compared with controls, showed significantly lower interintonative variations (both of Fo and of signal intensity). This deficit was particularly evident for expression of anger, which required an important increase in pitch and volume of sound. Moreover, the slopes of the last word for interrogation and affirmation were also lower in the patient group. This showed a poor ability to raise or decrease pitch at the end of a sentence to indicate a question or a declarative statement. These findings showed that patients with closed head injury had prosodic disturbances in both linguistic and emotional intonations. These deviant prosodic features are consistent with those reported by Theodoros et al with a perceptual analysis, ${ }^{4}$ who disclosed the presence of reduced variation of pitch and loudness in the speech of patients with closed head injury.

The mechanisms underlying dysprosody after closed head injury remain unknown. The ability to modulate speech output according to prosodic context is usually considered to depend on different factors. Dysprosody has 
been reported in a great variety of neurological or psychiatric conditions, such as right hemispheric lesions, left hemispheric lesions, Parkinson's disease, and depression or psychotic states. ${ }^{11}{ }^{17}$ 25-30 Mood disorders (depression) are known to alter pitch and loudness. ${ }^{17}$ However, it seems unlikely that such disorders could have influenced our findings for the following reasons. Firstly, no patient in our group had severe depression (none of them scored more than 21/60 at the MADRS); secondly there was no significant correlation between prosodic data and the depression scale. Another confounding factor that might have interfered with our results was the existence of more global cognitive or behavioural impairment (for example, disorders of attention, of short term memory, or poor motivation). This again seems unlikely, as there was no consistent significant correlation between prosodic production and the neurobehavioural assessment. This suggests that dysprosody in our patients cannot be attributed to a mood disorder or to a global neurobehavioural impairment, but rather to a defect in motor control of speech output. This hypothesis fits with the frequent occurence of dysarthria after severe closed head injury.

Acoustic analysis of pitch and volume illustrate aspects of speech disorders that are difficult to detect by the human ear on its own. The determination of the acoustic impairments is important to ensure appropriate planning of therapy and also to measure objectively the improvement of patients during follow up. ${ }^{31}$ Moreover, such analyses also offer the advantage of providing the patient with a visual feedback of his speech output. ${ }^{32}$ Further research should involve larger groups of patients with closed head injury and also include other measures such as stress of pronunciation and rhythm. Moreover, to further test the hypothesis that the problem with prosody in closed head injury is on the motor side it would be interesting to assess the receptive side of the prosody.

This study was supported by grants from the Institut Garches and from the Délégation à la Recherche Clinique, Assistance Publique-Hôpitaux de Paris. We are grateful to MC Ballet and P Delacou for their assistance.

1 Vogel M, von Cramon D. Dysphonia after traumatic midbrain damage: a follow-up study. Folia Phoniatr Logop midbrain damage

2 Ziegler W, Von Cramon D. Spastic dysarthria after acquired Ziegler W, Von Cramon D. Spastic dysarthria after acquired
brain Injury: an acoustic study. British fournal of Disorders of brain Injury: an acoustic study. B
Communication 1986;21:173-87.

3 Ziegler W, Von Cramon D. Vowel distorsion in traumatic dysarthria: a formant study. Phonetica 1983;40:63-78.

4 Theodoros DG, Murdoch BE, Schenery HJ. Perceptual speech characteristics of dysarthric speakers following severe closed head injury. Brain Inj 1994;8:101-24.
5 Aronson A. Laryngeal-phonatory dysfunction in closedhead injury. Brain Inj 1994;8:663-5.

6 Theodoros DG, Murdoch BE. Laryngeal dysfunction in dysarthric speakers following severe closed-head injury. Brain Inj 1994;8:667-84.

7 Monrad-Krohn GH. Dysprosody or altered melody of language. Brain 1947;70:405-15.

8 Monrad-Krohn GH. The third element of speech: prosody and its disorders. In: Halpern L, ed. Problems of dynamic neurology. Jerusalem: Hebrew University Press, 1963:10118.

9 Ross E. The aprosodias. In: Feinberg TE, Farah MJ, eds. Behavioral neurology and neuropsychology. New York: McGraw-Hill, 1997:699-709.

10 Keller E, Vigneux P, Laframboise M. Acoustic analysis of neurologically impaired speech. British fournal of Disorders of Communication 1991;26:75-94.

11 Teasdale G, Jennett B. Assessment of coma and impaired consciousness: a practical scale. Lancet 1974;ii:81-4.

12 Levin HS, Gary HE, Jr, Eisenberg HM, et al. Neurobehavioral outcome 1 year after severe head injury: experience of the traumatic coma data bank. F Neurosurg 1990;73:699709.

13 Greenwood R. Value of recording duration of posttraumatic amnesia. Lancet 1997;349:1041-2.

14 Jennett B, Teasdale G. Management of head injuries. Philadelphia: Davis, 1981.

15 Levin HS, O' Donnell VM, Grossman RG. The Galveston orientation and amnesia test. A practical scale to assess cognition after head injury. F Nerv Ment Dis 1979;167:67584 .

16 Deloche G, Metz-Lutz MN, Kremin H, et al. Test de dénomination orale de 80 images: DO 80. Paris: ECPA, 1997.

17 Nilsonne A. Speech characteristics as indicators of depressive illness. Acta Psychiatr Scand 1988;77:253-63.

18 Darby JK, Simmons N, Berger PA. Speech and voice parameters of depression: a pilot study. Fournal of Communication Disorders 1984;17:75-85.

19 American Psychiatric Association. Diagnostic and statistical manual of mental disorders (revision of the third edition: DSM III-R). Paris: American Psychiatric Association; French translation: Masson, 1989.

20 Keller E. Signalyze: signal analysis for speech and sound. 2.0 ed. Lausanne: Infosignal, 1992

21 Reitan RM. Validity of the trailmaking test as an indication of organic brain damage. Percept Mot Skills 1958;8:271-6.

22 Levin HS, High WM, Goethe KE, et al. The neurobehavioral rating scale: assessment of the behavioral sequelae of head injury by the clinician. $\mathcal{F}$ Neurol Neurosurg Psychiatry 1987;50:183-93.

23 Levin HS, Mazaux JM, Vanier M, et al. Evaluation des troubles neuropsychologiques et comportementaux des traumatisés crâniens par le clinicien: proposition d'une échelle neurocomportementale et premiers résultats de sa version française. Annales de Réadaptation et de Medecine Physique 1990;33:35-40.

24 Montgomery S, Asberg M. A new depression scale designed to be sensitive to change. Br F Psychiatry 1979;134:382-9.

25 Caekebeke JFV, Jennekens-Schinkel A, van der Linden ME, et al. The interpretation of dysprosody in patients with Parkinson's disease. I Neurol Neurosurg Psychiatry 1991;54: $145-8$.

26 Ross ED. The aprosodias: functional-anatomic organization of the affective components of language in the right hemisphere. Arch Neurol 1981;38:561-9.

27 Kent RD, Rosenbek JC. Prosodic disturbance and neurologic lesion. Brain Lang 1982;15:259-91.

28 Danly M, Shapiro B. Speech prosody in Broca's aphasia. Brain Lang 1982;16:171-90.

29 Hird K, Kirsner K. Dysprosody following acquired neurogenic impairment. Brain Lang 1993;45:46-60.

30 Murphy D, Cutting J. Prosodic comprehension and expression in schizophrenia. $\mathcal{F}$ Neurol Neurosurg Psychiatry 1990;53:727-30.

31 Theodoros DG, Murdoch BE, Stokes PD. Variability in the perceptual and physiological features of dysarthria following severe closed-head injury: an examination of five cases. Brain Inj 1995;9:671-96.

32 Stringer AY. Treatment of motor aprosodia with pitch biofeedback and expression modelling. Brain Inj 1996;10 583-90 